\title{
Editorial: Foundations of economic change - behavior, interaction and aggregate outcomes
}

\author{
Uwe Cantner $^{1,2} \cdot$ Andreas Pyka ${ }^{3}$
}

Published online: 1 October 2016

(C) Springer-Verlag Berlin Heidelberg 2016

Keywords Economic change $\cdot$ Economic evolution $\cdot$ Innovation $\cdot$ Micro-macro Economic behavior

\section{JEL classification $\mathrm{O} 31 \cdot \mathrm{O} 33 \cdot \mathrm{L} 16 \cdot \mathrm{D} 21$}

The theme of the 15th International Joseph A. Schumpeter Conference, held from July 27 to 30, 2014 in Jena (Germany), was "Foundations of Economic Change Behavior, Interaction and Aggregate Outcomes". This topic was intended first to cover core dimensions of innovation driven evolutionary economic development and to be broad enough to attract a wide range of papers from evolutionary economics, economics of innovation, science and technology studies, complexity economics, behavioral economics, institutional economics, regional economics, and others more. Secondly, the topic was chosen in order to represent the research achievements, agendas and programs that have been developed in Jena since 1991: institutionally to mention here are the Max Planck Institute of Economics with its focus on evolutionary and behavioral economics as well as entrepreneurship, completed by and cooperating with research projects on economics of innovation, behavioral economics and entrepreneurship at the Department of Economics and Business Administration at the Friedrich Schiller University, as well as the University's research major "Social and Economic

Andreas Pyka

a.pyka@uni-hohenheim.de

Uwe Cantner

uwe.cantner@uni-jena.de

1 Department of Economics and Business Administration, Friedrich Schiller University Jena, Jena, Germany

2 Centre for Integrative Innovation Management, Department of Marketing \& Management, University of Southern Denmark, Odense, Denmark

3 Institute of Economics, Innovation Economics, Universität Hohenheim, Stuttgart, Germany 
Change" with research projects in psychology, sociology, law, regional sciences, ethics, and political sciences; major research training groups located in Jena that trained and advised young scholars from all over the world have been pushing these research topics: the DFG graduate school (GRK 1411) "The Economics of Innovative Change", the International Max Planck Research School on "Adapting Behavior in a Fundamentally Uncertain World", and the Jena Graduate School "Human Behavior in Social and Economic Change". Third, and finally, the choice of behavior, interaction and aggregate outcomes followed a specific rationale: that of representing the multilevel focus of analysis and the 'division of labor' of Neo-Schumpeterian and Evolutionary economists that over the years committed themselves to uncover the dynamic nature of economic phenomena from the individual and single technology (in production and consumption) up to changes in whole systems. In this sense, the title of the conference was at the same time a tribute to (and a suggestion to proceed on) the inquiry of the Economy from a systemic and systematic viewpoint.

In July 2014, 369 scholars from all over the world, one third of which were young researchers, attended the Jena conference, discussed up-to-date problems and questions under the general topic's umbrella and presented 313 appropriate papers. The conference program was developed along seven plenary sessions, a final outlook session, as well as "semi-plenary" sessions and 89 parallel sessions. Each plenary session featured two eminent speakers - of which, usually one 'senior' and one 'junior' scholar, a decision taken with the declared aim to foster the intergenerational dialogue within the community -who discussed topics revolving around the main "building block" of the event, that is Behavior, Interaction, and Aggregate Outcomes, developed along the following themes: Behavioral Foundations, Complexity Economics and Innovation, Industrial Dynamics, Schumpeter meets Keynes?: ABM and the "Macro", Smart Specialization and Innovation Policies, Entrepreneurship in Context, as well as Productivity and Innovation. A final outlook session on The Future of Capitalism completed this sequence. It was a pleasure to listen to the inspiring talks of W. Brian Arthur, David B. Audretsch, Giulio Bottazzi, Guido Bünstorf, Wesley Cohen, Herbert Dawid, Giovanni Dosi, Magda Fontana, Dominique Foray, Koen Frenken, Daniella Laureiro, Mariana Mazzucato, Stan Metcalfe, Pierre Mohnen, Richard R. Nelson, Carlotta Perez, Mario Pianta, and Ulrich Witt. The semi-plenary sessions were dedicated to topics considered of high interest and potential and of wider interest: Core Issues in ABM, Evolutionary Economics: Welfare, Entrepreneurship: Behavior and Traits, Core Issues in Innovation, From Micro to Macro, Demand and Evolution of Preferences, Europe in a Globalized World, Schumpeter and Keynes, Core Issues in Industrial Dynamics.

This special issue represents the breadth of the discussion during the Jena conference and addresses behavioral dimensions of economic change, the mechanisms of actor interaction driving change, and the aggregate outcomes of these interactions. The collection here is the result of a review process and selection of a larger number of papers submitted after the conference.

The special issue starts with Uwe Cantner's Presidential Address entitled Foundations of Economic Change, which has to be considered the intellectual skeleton of this volume. Understanding the process of change, either incremental or disruptive, is the core of the Schumpeterian research program. The Presidential Address includes a broad theoretical analysis supplemented by empirical accounts of endogenous processes of change and development which places heterogeneous actors and their interaction 
central. For this purpose, Uwe Cantner also borrows important insights from behavioral and complexity economics, however keeping a critical eye open on the mainstream side of economic theory, so to be able to present Neo-Schumpeterian economics as a valid alternative for a comprehensive study of economic phenomena. The result is at the same time a consistent review of contributions at the different level of analysis, conflating the 'division of labor' mentioned above, and a roadmap for the research to come. In his paper Behavior and Cognition of Economic Actors in Evolutionary Economics Richard Nelson develops further considerations concerning routinized and creative behavior of economic agents. He highlights the importance of the evolving framework of cultural context in which explorative and exploitative human agents are embedded in, and which is responsible for adaptive responses. Needless to say that this kind of behavior does not resemble any optimization but is coping with the complexity of the real world. Kurt Dopfer, Jason Potts and Andreas Pyka address the issue of an endogenously evolving environment in which economic agents are embedded in and which in turn is shaped by the actions and interactions of economic agents. In their paper Upward and downward complementarity: The meso core of evolutionary growth theory the authors show that a major source for the qualitative changes economic systems undergo over time, comes from cross-fertilization of so far not connected knowledge, which is behind upward complementarities. Upward complementarities are responsible for the long-run innovative changes causing qualitative change and structural development so central in evolutionary economics.

The first three contributions of this special issue show that we have to expect rather heterogeneous aggregate outcomes in different economic systems, caused by differences in the capabilities of economic agents interacting in market and non-market environments. Heterogeneity is, therefore, a fundamental property not only of firms, but of wider economic systems too. Martin Shrolec's paper entitled Global Dynamics, Capabilities and the Crisis exactly addresses these issues from an empirical point of view in his analysis of the consequences of the 2007 financial crisis which is far from being uniquely processed in Europe, Asia and Africa. Maureen McKelvey also addresses the context dependence as an important explanation for varying innovation performance of firms in her contribution Firms Navigating through Innovation Spaces: A Conceptualization. Innovation activities of firms are embedded in different geographical contexts which are responsible for access, generation and co-evolution of ideas in R\&D cooperations. The specific mix of available resources, technologies, creative people stimulate business innovation and leads to rather heterogeneous products, process and services. The replicator dynamics approach already used by Uwe Cantner in his Presidential Address also is central in the paper Confounded, augmented and constrained replicator dynamics - Complex selection processes and their measurement by Jacob Rubæk Holm, Esben Sloth Andersen and J. Stanley Metcalfe. An extension of replicator dynamics to overcome the restrictions stemming from the concentration of a single characteristic evolving in a single environment is introduced. So-called confounded selection becomes visible by considering the co-variance matrix of heterogeneous characteristics, which opens opportunities for new empirical analysis building on replicators.

Guido Bünstorf, in his contribution Schumpeterian incumbents and industry evolution, sheds light on an observation most often not so in the foreground, namely the creative role of established companies. Incumbents provide fertile grounds for innovative spin-offs by both allowing the foundation of new companies and also by acquiring 
entrepreneurial companies to support the diffusion of new technologies. Also when it comes to industry-university relationships incumbents often offer better prerequisites to digest and integrate new basic knowledge. Traditionally, external knowledge flows are considered as involuntary externalities and are summarized under the heading of technological spillovers. As this special issue in particular emphasizes that heterogeneity matters, also external knowledge sources are to be considered in more detail as there a vast differences between e.g. innovation networks and industrial espionage. Muhammad Ali, Uwe Cantner and Ipsita Roy in their contribution Knowledge Spillovers through FDI and Trade: Moderating Role of Quality-Adjusted Human Capital shed new light on the particularities of foreign direct investments and thereby help to disentangle the confusion around technological spillovers. In their empirical analysis they employ a quality-based indicator of human capital to investigate the varying effects of FDI in 20 European economies between 1995 and 2010. Dario Guarascio, Mario Pianta and Francesco Bogliacino also investigate European industries and find characteristic patterns which distinguish between Northern economies and Mediterranean economies. Their contribution Export, $R \& D$ and New Products. A Model and a Test on European Industries focuses on three relationships explaining the varying innovative performance in the two groups of countries, namely the capacity of firms to transfer R\&D into new products, the meaning of innovation to gain export market shares and the relationship between successful exports and innovation. In the Northern economies a positive feedback emerges which is missing in the other countries club. Thomas Brenner and Johann Peter Murmann apply simulation analysis to explain the different settings of the German and the U.S. synthetic dye industries dominating the evolution of this industry in the second half of the 19th century. Their numerical experiments in their paper Using Simulation Experiments to Test Historical Explanations: The Development of the German Dye Industry 1857-1913 show the important role of University-Industry-links responsible for the global dominance of German companies in this field.

To conclude, all contributions in this special issue emphasize the role of heterogeneity of economic actors concerning e.g. their knowledge-base, the meaning of different modes of interaction between various actors within economic systems as well as the important mutual feedback relations between the economic agents and their environment responsible for varying contexts in which innovation-driven dynamics take place. Without doubt, the explicit emphasis on the overwhelming heterogeneity to be observed in different realms of economic systems is responsible for the extra explanatory power of modern evolutionary economics. Finally, and besides the stress on the idea that 'heterogeneity matters', all the contributions in this special issue have to be praised as they ennoble the general guideline traced by the Conference title 'Foundations of Economic Change'. The papers extend, enrich and deepen our understanding of processes of evolution and change at all the levels of analysis, and certainly push forward the frontier of knowledge, to the benefit of the NeoSchumpeterian and Evolutionary Economics community of scholars. In this sense, this special issue is a taste of a more general academic success and should be considered as an additional evidence of the increasing relevance of the topics at the core of the Journal of Evolutionary Economics' attention; for all these reasons, we are convinced that the special issue will become a source of insight, motivation, and inspiration for a wave of novel research in the spirit of Schumpeter. 